\title{
Investigation of echo sounding parameters for the characterisation of bottom sediments in a sub-tropical reservoir
}

\author{
Stephan Hilgert, ${ }^{*}$ Adrian Wagner, Lisa Kiemle, Stephan Fuchs \\ Institute for Water and River Basin Management (IWG), Division of Aquatic Environmental Engineering (ISWW), Karlsruhe Institute \\ of Technology (KIT), Gotthard-Franz-Str.3, Bld. 50.31, 76131 Karlsruhe, Germany \\ *Corresponding author: Stephan.hilgert@kit.edu
}

\begin{abstract}
The increasing number of reservoirs around the world today reaches a surface area of around 500,000 $\mathrm{km}^{2}$, equalling one third of that of non-artificial surface water bodies. By impounding rivers through the construction of dams, riverine systems and biochemical cycles are disrupted. Different types of transported materials are trapped behind the dams and form layers of sediment. A comprehensive combination of two frequencies with four pulse lengths were tested in order to classify multiple physical and chemical sediment parameters in the Vossoroca reservoir in the southeast of Brazil, Paraná State. A number of core and grab samples was taken and analysed for a variety of chemical and physical parameters. These data served as ground truthing for the hydro-acoustic assessment of the sediment. Eight hydro-acoustic parameters were derived from the echo signals obtained with an EA 400 system using the Sonar5-Pro software. The major objective of defining the optimal survey parameters for the echo sounder as well as determining the difference between core and grab samples was reached by correlating the various single parameters and identifying the best combinations. Density and grain size distribution represented the best detectable sediment features with $r$-values of 0.94 and 0.95 . The lower $38 \mathrm{kHz}$ frequency generally had a better performance than the $200 \mathrm{kHz}$ frequency. Results show that core samples reached a significantly higher quality of correlation for sediment characterisation. Additionally, it was found that shorter pulse lengths yield a better characterisation. The results underline the potential of single beam echo sounders for extensive sediment characterisation. This methodology may be used for future mass balance estimations of large reservoirs.
\end{abstract}

Key words: Echo sounding; sediment characterisation; pulse length; sediment sampling; SBC, reservoir.

Received: November 2015. Accepted: June 2016.

\section{INTRODUCTION}

About 50,000 reservoirs with dams higher than $15 \mathrm{~m}$ exist in the world and many huge dam construction projects are in the planning phase (WCD, 2000). Especially in the tropics and sub-tropics, the number of recently constructed reservoirs is high. The area covered by those reservoirs is increasing and already makes up an area of about $500,000 \mathrm{~km}^{2}$, which equals one third of the surface area of non-artificial surface water bodies (WCD, 2000).

By impounding rivers through the construction of dams, riverine systems and biochemical cycles are disrupted (Friedl and Wüest, 2002). Suspended solids and transported material are trapped and settle in the reservoirs (Odhiambo and Boss, 2004). The sediment quality and amount of sediment have a direct influence on the management of the reservoir as well as on water quality in the reservoir.

It is therefore necessary to characterise and manage the accumulated sediment volumes. As the spatial dimensions of many of the reservoirs are huge, it is still a problem to obtain representative data for several quality parameters of the sediment. Echo sounding systems have been found to allow for a time- and cost-saving data acquisition, especially when they are used on larger spatial scales (Freitas et al.,
2006; Anderson et al., 2008; Poulain et al., 2011). They represent the most promising approach to extensive sediment classification apart from traditional point sampling techniques like grab sampling and sediment coring. Multibeam echo sounders (MBS) and swath systems provide the highest coverage of area in relation to needed vessel time, but are inherently more expensive than single beam echo sounders (SBS). In regards of seabed classification literature shows successful studies for MBS (Bentrem et al., 2002; Preston, 2009; Hamilton and Parnum, 2011) and SBS (Tęgowski, 2005; Anderson and Pacheco, 2011; Poulain et al., 2011), both systems have advantages and disadvantages. MBS and SBS provide high accuracy during seabed classification. However, the SBS need dense line spacing for comparable spatial results. The SBS features the advantage that the second bottom echo can also be integrated in the seabed classification (Parnum et al., 2009). Systems like the Simrad EA 400 use two frequencies at the same time, which may improve the sediment classification due to a lower second frequency, which allows for a better classification of the volume characteristics due to deeper sediment penetration. Independent from the selected echo sounder, the classification of sediment parameters is still largely limited to physical parameters, such as grain size distribution. Few re- 
sults have been published so far with respect to correlations between other sediment parameters, e.g. organic content, iron content, phosphate content, and loss on ignition, and hydro-acoustic parameters. Next to the influence of the named sediment parameters, this study investigates different pulse length in order to find optimal configurations for seabed classification. Apart from the best echo sounder configuration for the detection of the parameters listed, the influence of the sediment sampling method was investigated. Since grab and core sampling produce different sediment sample types, a significant influence on the ground truthing results can be expected. Most of the data published refer to the correlation of hydro-acoustic information with grab samples taken by e.g. an Ekman dredge (Bentrem et al., 2002; Amiri-Simkooei et al., 2011; Anderson and Pacheco, 2011; Poulain et al., 2011; Anderson and Martinez, 2015). Several well-established commercial echo sounding systems and related software for lakebed classification are available on the market (i.e., QTC View, etc.), internal data processing, however, is a black box to the user. We used a combination of a Kongsberg EA 400 single beam echo sounder with frequencies of 200 and $38 \mathrm{kHz}$ and the sediment classification tool of the Sonar5-Pro post-processing software for lakebed characterization. The formulas for the seabed classification used in the Sonar5-Pro software are openly documented and intermediary results can be exported and processed e.g. in a combination with MATLAB (Mathworks ${ }^{\circledR}$ ) (Balk et al., 2011).

The data were collected in March and November 2011 during two surveys of the Vossoroca reservoir in the southeast of Brazil. During the first campaign, bathymetry of the entire reservoir was obtained in a rather dense grid. The maximum depth of the reservoir was found to reach 17 metres. Subsequently, a 3D model was created, which served to plan the following survey in November. Eight different hydro-acoustic parameters were derived from the echo signals for later correlation with the sediment properties at the corresponding locations. The sediment properties included physical parameters, such as grain size distribution, but also chemical parameters, such as phosphorus and iron contents. In addition to the standardised 'first echo division method' and 'first/second bottom ratio method' (Burczynski, 1999), further signal parameters extracted by the sediment classification tool of the Sonar5Pro software were tested with respect to their correlations with sediment parameters obtained by ground truthing and at changed pulse durations.
This study was aimed at finding the optimal echo sounder configuration for the characterisation of sediments using a non-commercial software. Additionally, the influence of the sediment sampling method was analysed.

\section{METHODS}

\section{Study area}

The Vossoroca reservoir is located in southern Brazil in the state of Paraná, approximately $50 \mathrm{~km}$ southeast of $\mathrm{Cu}-$ ritiba in the 'Serra do Mar' mountain range at approximately $833 \mathrm{~m}$ asl. The annual rainfall is about $1900 \mathrm{~mm}$, the climate is subtropical. The reservoir, which covers an area of about $5 \mathrm{~km}^{2}$ and has a capacity of $33.6 \times 10^{6} \mathrm{~m}^{3}$ (Republic of Brazil, 1969), was created in 1940 to control water flow for the Chaminé hydroelectric power plant located $7 \mathrm{~km}$ downstream. The average water depth is about $8 \mathrm{~m}$, maximum depth is about $17 \mathrm{~m}$. The catchment area of the reservoir has a size of $151 \mathrm{~km}^{2}$ (Republic of Brazil, 1969 ) and is predominantly rural. The immediate surroundings of the reservoir are used for recreation, whereas the upstream area of the basin is mainly used by agriculture. The major part of the reservoir belongs to the nature protection area of Guaratuba.

Bathymetric survey covered the entire lake except for the very shallow parts (less than $1.30 \mathrm{~m}$ ). In these areas, no proper echo signal could be received and the risk of running aground was too high. Fig. 1 shows the bathymetric measurement grid. Point sampling focused on the left arm and the central part of the reservoir to facilitate the sampling process (Fig. 2).

\section{Hydro-acoustic data acquisition}

A Kongsberg EA 400 single beam echo sounder with frequencies of 200 and $38 \mathrm{kHz}$ was used for the acquisition of hydro-acoustic data. Tab. 1 reports the echo sounder characteristics. The EA 400 features opening angles of $7^{\circ}$ for $200 \mathrm{kHz}$ and longitudinal and transverse angles of $13^{\circ}$ and $21^{\circ}$, respectively, at $38 \mathrm{kHz}$. The survey was carried out to characterise the lakebed under very shallow conditions (2-17 $\mathrm{m}$ depth). The transducer was mounted vertically $\left(0^{\circ}\right.$ angle $)$ on the starboard side of a small aluminium vessel, $67 \mathrm{~cm}$ below the water surface to prevent surface bubbles from interfering with the meas-

Tab. 1. Overview of the EA 400 echo sounder characteristics.

\begin{tabular}{lccccc} 
Frequency & Opening angle (longitudinal) & Opening angle (transverse) & Pulse length (ms) & Power input (W) \\
$200 \mathrm{kHz}$ & $7^{\circ}$ & $7^{\circ}$ & $0.064 ; 0.128 ; 0.256 ; 0.512$ & $100-1000$ \\
$38 \mathrm{kHz}$ & $13^{\circ}$ & $21^{\circ}$ & $0.256 ; 0.512 ; 1.024 ; 2.058$ & $100-1000$ \\
\hline
\end{tabular}


urements. The average vessel speed was about $2 \mathrm{~m} \mathrm{~s}^{-1}$. Due to the calm weather and, hence, the absence of waves, the influence of pitch, roll, and heave could be neglected. Every day before the acoustic measurements, the actual water level of the reservoir was determined with the help of a reference pole. In this way, the acoustic signals could be referenced to the same water level and merged and compared. In addition, a temperature and a conductivity profile were recorded daily and both data were included in signal correction during post-processing. The temperature and conductivity profiles were used to correct the sound speed in the water phase during postprocessing. A Leica GPS 1200+ was used during all measurements. A RTK base station was positioned on a close by hill to allow for high precision of the positioning, below $1 \mathrm{~m}$ accuracy. The GPS was connected to the notebook and transmitted the position signal to the EA 400 software. The ground at each position was sounded for the duration of at least 300 pings using the EA 400 echo sounder. As the survey focused on the potential of the echo sounder to obtain sediment characteristics, variable pulse length combinations at both frequencies were used, thus resulting in a data set of 300 pings per configuration and four configurations at each of the 32 positions. Eight different hydro acoustic parameters were derived from the echo signals for later correlation with the sediment properties at the corresponding locations.

\section{Bathymetric survey}

The bathymetric survey of the entire reservoir was made along a pre-defined survey grid. The transverse lines of the general survey grid had a track distance of approximately 50 to $100 \mathrm{~m}$, while the western arm of the reservoir was surveyed at higher resolution. Higher numbers of transverse lines were chosen to allow for better detec-

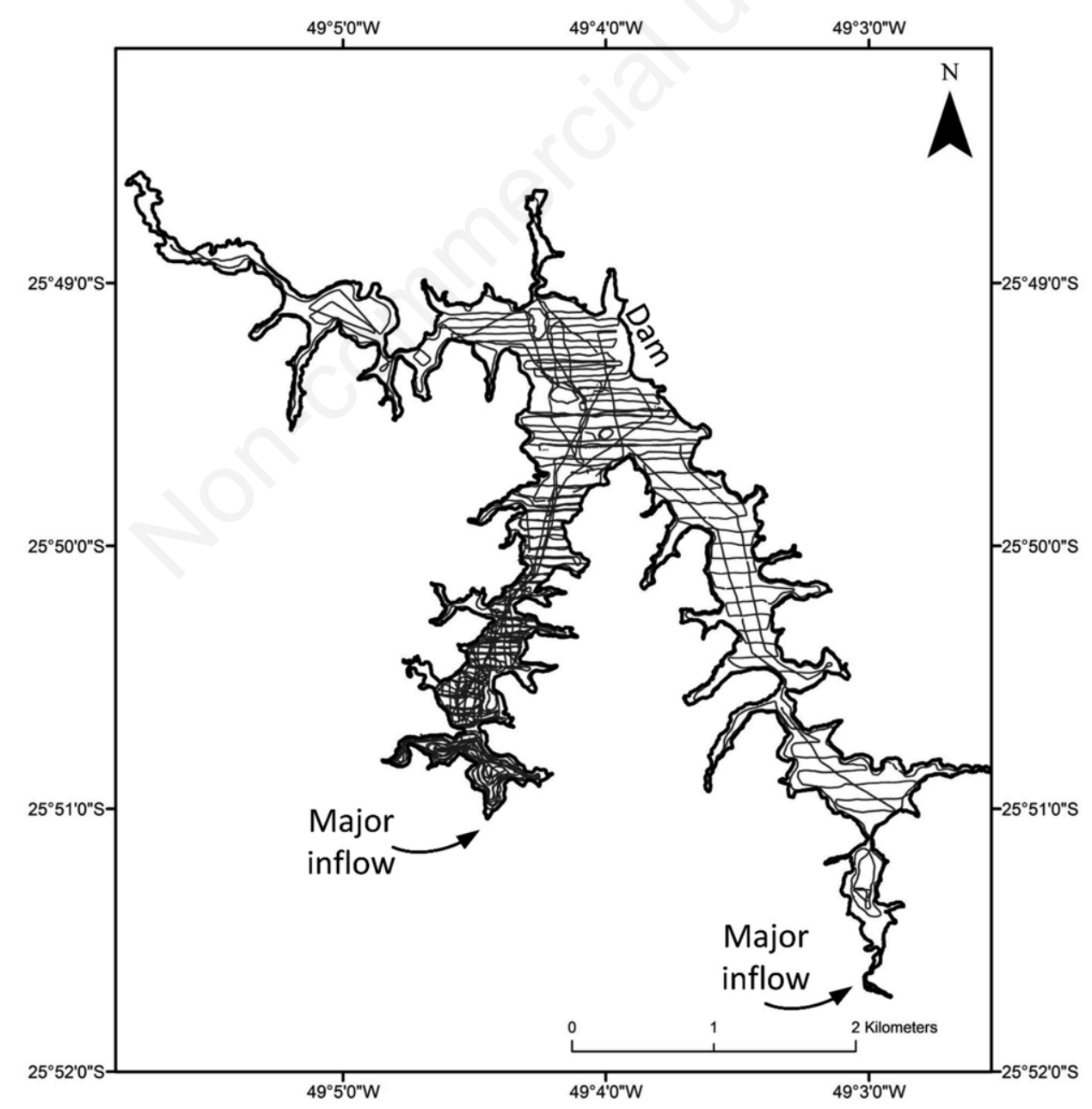

Fig. 1. Driven raster of the bathymetric survey in the Vossoroca reservoir; the grey lines represent the driven tracks of the boat. 
tion of steep slopes. In addition to the longitudinal and transverse lines, a route close to the reservoir banks was driven to obtain a more complete data set of the shallow parts of the reservoir.

To drive the boat along the pre-defined grid lines, a compass was installed on the boat for undelayed course correction. While measuring, the boat was kept as calm as possible, fast acceleration and swinging were prevented in order to reduce distorted signal detection. Small changes in in heave, role or pitch were neglected during the bathymetric study. The measurements were carried out at both frequencies with a pulse length of $0.256 \mathrm{~ms}$ and a ping rate of 20 pings per second. The power input was set to $100 \mathrm{~W}$ to prevent non-harmonic distortions at $200 \mathrm{kHz}$.

\section{Sediment characterisation}

Depth distribution of the digital lake model was used as a basis for the positioning of the sediment sampling points. The positions were selected in transect lines perpendicular to the general geomorphological shape and the former river bed (Fig. 2). In case of very steep slopes or other inaccessible locations, the sample sites were shifted from the transects to the next possible position. During the second survey, 11 sediment cores and 21 grab samples were collected at 32 different positions. Bathymetric information was used to select sampling positions, including not only the depth spectrum, but also site characteristics. To increase the density of the sampling points, the left arm and the central part of the reservoir were selected for detailed investigation. All sampling points were located in this part of the reservoir. The vessel was anchored with three anchors to ensure a stable position during the sampling and echo sounding phase. No movement of the boat occurred during data acquisition. Ensonification of the sediment with the echo sounder was carried out before disturbing the sediment by taking core or grab samples. Four different configurations were used

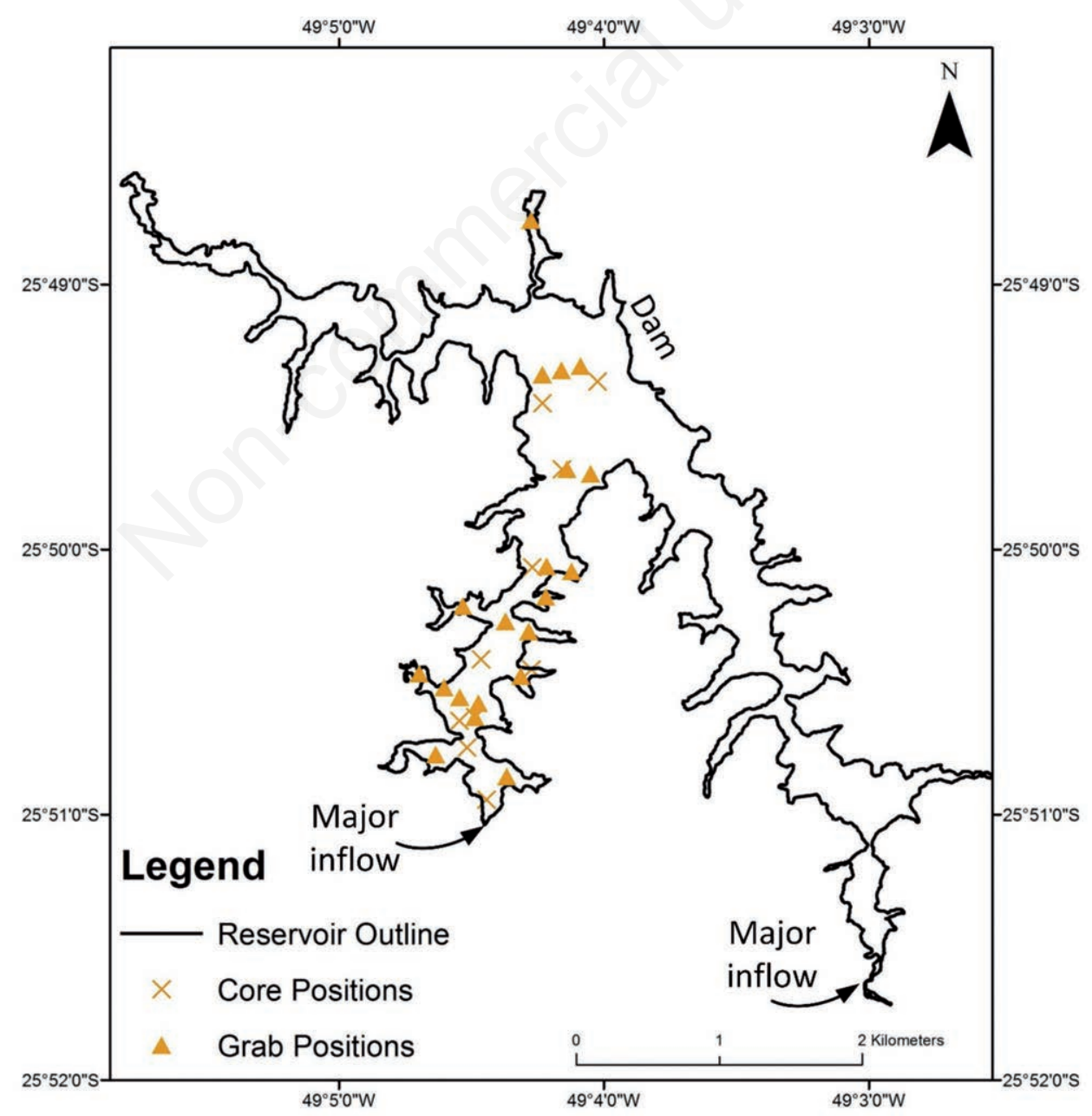

Fig. 2. Positions of the core and grab sampling sites in the Vossoroca reservoir. 
in order to find the best setting for sediment characterisation (Tab. 2). All configurations were set to an input power of $100 \mathrm{~W}$.

As the variability of the signal between two successive pings may be high (Burczynski, 1999), the echo sounder was set to all configurations one after another and each sampling position was ensonified for the duration of approximately one minute with 5 pings per second, resulting in a minimum of 300 pings per sampling point and configuration. Bottom detection was carried out using the Sonar5-Pro bottom detection tool (Balk et al., 2011). As a threshold for bottom detection, $-36 \mathrm{~dB}$ was chosen, as it showed best results for the automatic detection of the sediment water interface. Each detected bottom line was controlled manually on pixel level to ensure correctness of bottom detection (e.g., to exclude trunks). Post-processing of the echo sounder data resulted in a set of eight parameters for each ping (Fig. 3). Afterwards, all erroneous and extreme values were sorted out and mean values of the
300 pings were calculated for all eight parameters. This processing step was conducted in MATLAB R2014a $\left(\right.$ Mathworks $\left.^{\circledR}\right)$.

According to the different phases of bottom ensonification, the signal of an echo is divided into two parts (E1' and E1) as shown in Fig. 3 (Burczynski, 1999). The first part covers the attack phase (duration: one pulse length from the bottom detection point) and the second the decay phase (duration: three pulse lengths from the end of the attack phase).

As that part of the echo, which is created during the attack phase, is mainly caused by the bottom surface, the energy of this part of the echo (E1') can be used as a measure of acoustic hardness or reflectivity. The part of the echo created during the decay phase is caused by diffuse backscattering from the sediment volume. As scattering depends on bottom roughness, the energy of this second part of the echo (E1) is generally described as acoustic roughness (Burczynski, 1999).

Tab. 2. Overview of the four EA 400 echo sounder configurations with different pulse lengths.

\begin{tabular}{lcccc} 
Frequency $(\mathbf{k H z})$ & $\begin{array}{c}\text { Configuration A } \\
\text { pulse length }(\mathrm{ms})\end{array}$ & $\begin{array}{c}\text { Configuration B } \\
\text { pulse length }(\mathbf{m s})\end{array}$ & $\begin{array}{c}\text { Configuration C } \\
\text { pulse length (ms) }\end{array}$ & $\begin{array}{r}\text { Configuration D } \\
\text { pulse length (ms) }\end{array}$ \\
38 & 0.256 & 0.256 & 0.256 & 0.512 \\
200 & 0.064 & 0.128 & 0.256 & 0.512 \\
\hline
\end{tabular}

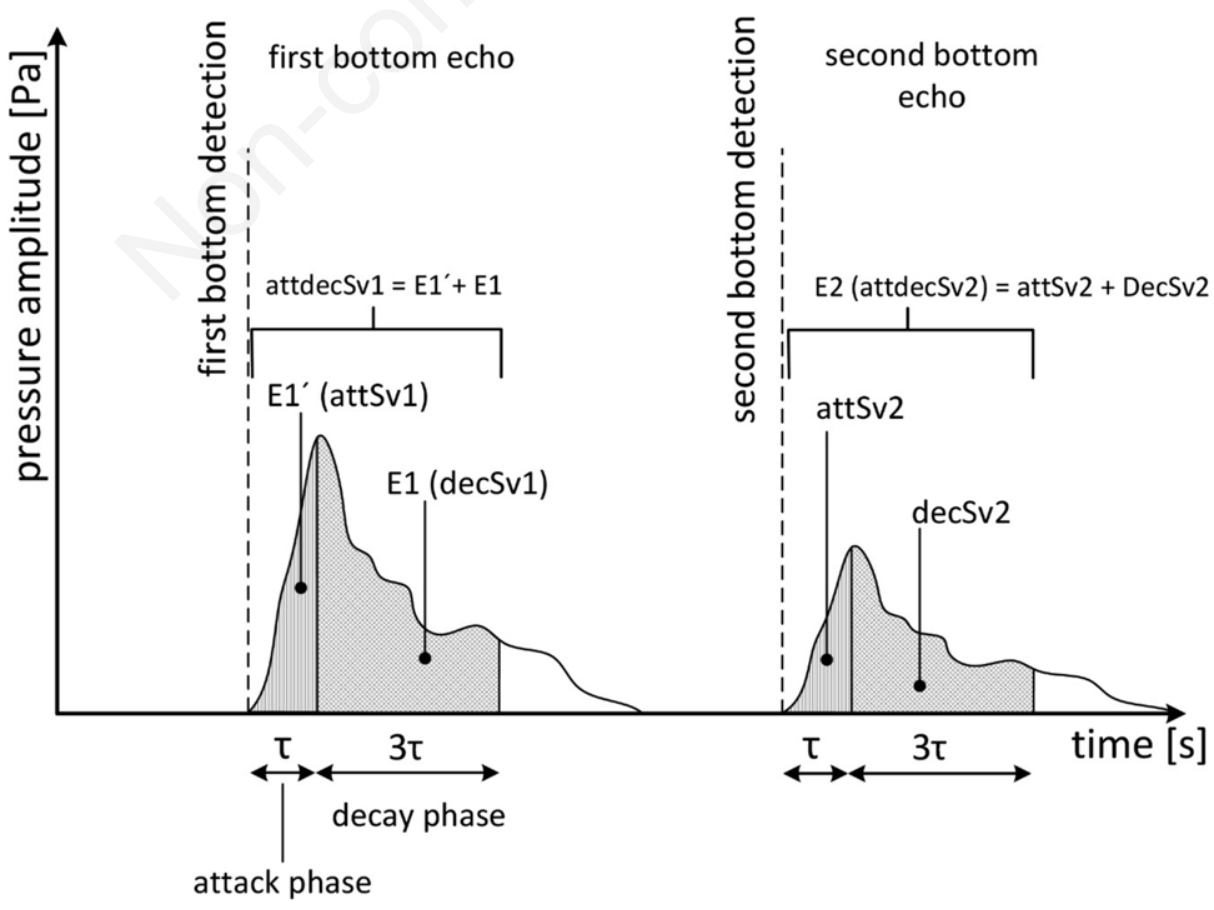

Fig. 3. Division of the first (left side) and second (right side) bottom echo into six basic hydro-acoustic parameters. 
Using the Sonar 5 Seabed Classification Tool, the attack value (hardness/ AttSv1/ E1') and decay values (roughness/ decSv1/ E1) were exported for the first bottom echo as well as for the second bottom echo, respectively the first multiple reflection (attSv2 and decSv2) (Fig. 3). attSv2 and decSv2 sum up to the E2 value for the entire second bottom echo. attSv1 (E1') and decSv1 (E1) describe the average volume backscattering strength Sv1 [dB] during the attack and decay phases of the first echo, respectively (Orlowski, 1984). To calculate the average volume backscattering strength during either attack or decay phase, the echo strengths $\left(\mathrm{Sv}_{\mathrm{i}}\right)$ of each single sample belonging to that phase are converted into intensities, summarised, divided by the number of samples, and converted back into a $\mathrm{dB}$ value (equations 1 and 2) (Balk et al., 2011). This was performed for the first as well as for the second bottom echo.

$$
\begin{aligned}
& \operatorname{attackSv1}\left(E 1^{\prime}\right)=10 \log \left[\frac{1}{N_{A}} \sum_{i=A I_{1}}^{A I_{2}}\left(10^{\frac{S v 1_{i}}{10}}\right)\right][d B] \\
& \operatorname{decaySv} 1(E 1)=10 \log \left[\frac{1}{N_{D}} \sum_{i=D I_{1}}^{D I_{2}}\left(10^{S v 1_{i}} \frac{10}{10}\right)\right][d B]
\end{aligned}
$$

In addition to the 'basic' attack and decay values, two values derived from the 'first echo division method' $(\mathrm{E} 1$ '/E1) and the 'first/second bottom ratio method' (E1/E2) (Orlowski, 1984) were exported.

As further parameters, one value representing the reflected energy of the entire first bottom echo 'attdecSv1' (E1) and one value for the entire second bottom echo 'attdecSv2' (E2) were calculated (Fig. 3). To obtain the average backscattering strength of the entire first second bottom echoes, respectively, $\operatorname{attSv}_{\mathrm{x}}$ and $\mathrm{decSv}_{\mathrm{x}}$ of the first and second echoes are converted into intensities. Then, they are weighted using the attack and decay samples $\left(\mathrm{N}_{\mathrm{A}}\right.$ and $\mathrm{N}_{\mathrm{D}}$, summarised, divided by $\left(\mathrm{N}_{\mathrm{A}}+\mathrm{N}_{\mathrm{D}}\right)$, and converted back into a dB value using equations 3 and 4 (Balk et al., 2011).

attackdecayS $1=$

$10 \log \left[\frac{1}{N_{A}+N_{D}}\left(N_{A} \cdot 10^{\text {attackSv } 1 / 10}+N_{D} \cdot 10^{\text {decaysv } 1 / 10}\right)\right]$

$\operatorname{attackdecaySv2}(E 2)=$

$10 \log \left[\frac{1}{31}\left(8 \cdot 10^{\frac{\text { attackSv2 }_{i}}{10}}+23 \cdot 10^{\frac{\text { decaySv2 }_{i}}{10}}\right)\right]$

In Sonar 5 the number of attack samples $\left(\mathrm{N}_{\mathrm{A}}\right)$ is 8 , but the first sample that should be integrated into the decSv value is used for the calculation of neither attSv nor decSv. Thus, the number of decay samples $\left(\mathrm{N}_{\mathrm{D}}\right)$ is 23 instead of 24, which must be considered in the formula when calculating E2 (Poulain et al., 2011).

\section{Sediment data acquisition (ground truthing)}

Eleven sediment cores were taken from water depths between 2 and 15.7 metres. An elongated version $(80 \mathrm{~cm})$ of the 'Mondsee' gravity corer by Uwitech (Niederreiter, 2012) was used to allow for a higher core penetration depth, as it was expected that the lower frequency is able to deeper penetrate soft sediment (Dunbar et al., 1999). In addition to core sampling, 21 grab samples were taken using a Petersen Grab Sampler (US Environmental Protection Agency (EPA), 2001). The material was put into a Whirl Paks ${ }^{\circledR}$ (Nasco) sampling bag of two litres in volume until analysis.

Steep slopes and rocky sea beds proved to be harder to sample properly, as both sampling devices may tilt during sampling or rocks prevent the jaws from closing. Unlike the Uwitech Corer, the grabber samples the top $15 \mathrm{~cm}$ of the deposits only and the fine fraction can be washed out partly during grabber recovery.

Sediment samples from both coring and grabbing were analysed for granulometry, loss on ignition (LOI), organic carbon content, and wet bulk density (cores only) (Harris et al., 2008). Sediment sample fractions smaller than $63 \mu \mathrm{m}$ were separated and additionally analysed for the contents of iron, phosphorus, and manganese. Determination of granulometry was accomplished by wet sieving of the samples (Deutsches Institut fuer Normung e.V., 2005), as the use of water guarantees that agglomerates dissolve and the particles are classified as the correct grain size. To obtain five classes of grain size, sieves with mesh widths of $2 \mathrm{~mm}, 500 \mu \mathrm{m}, 250 \mu \mathrm{m}$, and $63 \mu \mathrm{m}$ were used. The LOI was measured according to DIN EN 15169:2007, Deutsches Institut fuer Normung e.V., (2007). Between 2-5 g of each air-dried sample were filled into ceramic pots and weighed on a high-precision scale. They were then dried for $12 \mathrm{~h}$ at $105^{\circ} \mathrm{C}$, cooled to room temperature in a desiccator, and weighed again. Afterwards, the samples were burnt for two hours in a muffle furnace at $550^{\circ} \mathrm{C}$, cooled down, and weighed again to determine the LOI. As the sediment structure of the inner core is assumed not to be disturbed during core sampling, the wet bulk density of core samples in contrast to grab samples can be determined. This assumption was made, based on the visual findings that only the outer millimetres were affected by the impact of the tube and that the inner part of the $9 \mathrm{~cm}$ diameter was intact. The water saturated upper layer of the sediment settled again in most cases after the impact of the corer. A cylinder of fixed volume $\left(17.6 \mathrm{~cm}^{3}\right)$ was used to cut material out of the undisturbed inner core sample. From the weight of the fresh core material and the volume of the cylinder, the wet bulk density of the sediment was calculated. Density was determined for each visual distinctive core layer and a vertical average was calculated for later correlation.

Due to the high share of fine particles in the sediment, 
chemical analyses concentrated on the silt and clay fractions. Total carbon was determined using an Eltra CS 2000 Carbon Sulfur Determinator. The organic carbon content was calculated by subtracting the inorganic carbon content from the total carbon. Total phosphorus was determined in the form of phosphate by molybdate blue analysis according to DIN 38405-11. The iron content was measured using flame atomic absorption spectrometry (Perkin-Elmer 1100B) and manganese content was measured using graphite furnace atomic absorption spectrometry (Perkin-Elmer Simaa 6000).

\section{RESULTS}

\section{Sediment data (ground truthing)}

In all samples taken the silt and clay fraction was predominant. It accounted for an average weight of $74 \%$, with a minimum of $15.5 \%$ and a maximum of $99.7 \%$. However, about half of the sediment samples consisted almost completely $(>90 \%)$ of silt and clay, whereas the other half contained considerable percentages of coarser fractions (fine, medium, and coarse sand and gravel). The LOI ranged from $2.9 \%$ to $18.7 \%$. Wet bulk density values of the core samples varied from $1.08 \mathrm{~g} \mathrm{~cm}^{-3}$ to $1.61 \mathrm{~g} \mathrm{~cm}^{-3}$. The density of the cores correlated with various other sediment parameters, e.g. the share of particles smaller than $63 \mu \mathrm{m}$ $(r=-0.79)$, loss on ignition $(r=-0.88)$, phosphorus $(r=-0.80)$ and $\mathrm{Mn}$ contents $(r=-0.72)$. Principal results of sediment analysis of all samples are given in Tab. 3 .

\section{Hydro-acoustic survey}

To obtain a gapless 3D surface of the lake ground, the data of the bathymetric survey in the defined grid (100x50 $\mathrm{m})$ were interpolated using the Inverse Distance Weighting (IDW) method (ArcGIS 10.2, ESRI). The bathymetric map shows a general depth gradient from the two major inflows to the dam with a depth maximum in front of the dam (Fig. 4). The old river beds are still visible and represent the deepest depressions for each cross-section of the side arms. Small branches have relatively shallow depths. The outer shape as well as the depth distribution illustrate the high morphometric complexity of the Vossoroca reservoir.

\section{Relationships between sediment and hydro-acoustic parameters}

To assess the use of the hydro-acoustic parameters for sediment characterisation and prediction, all combinations of relevant parameters were correlated. Prior to the regression analyses, the sediment data sets were checked for normal distribution using the Shapiro-Wilk and Kolmogorov-Smirnov tests. With a confidence level of 5\%, p-values of 0.77 for the Kolmogorov-Smirnov test and around 6.2 for the Shapiro-Wilk test were reached, which confirmed the normal distribution of the data sets. Consequently, the analyses applied are statistically legitimate. Tabs. 4 and 5 list the Pearson $r$-values for the core samples and the grab samples. The 38 and $200 \mathrm{kHz}$ frequencies are shown next to each other for direct comparison. Rvalues above the significance level are highlighted (core samples: $\mathrm{P}<0.05$ for $r=0.63, \mathrm{n}=10$; grab samples: $\mathrm{P}<0.01$, $r=0.55, \mathrm{n}=21$ ). For both sample types, the average performance of the lower frequency is clearly higher. In addition, the correlation with core samples reaches higher levels of conformance. The best detectable parameter is 'density'. Independently of the hydro-acoustic parameters, it reaches an average $r$-value of 0.62 and maximum $r$-values of 0.94 . Additionally, high correlations are reached between the particle composition and most hydroacoustic parameters. Here, the best couple, $\%<63 \mu \mathrm{m}$ with $E 1$, reaches an r-value of 0.95 .

Tab. 3. Sediment key parameters from cores and grabs taken in Vossoroca Reservoir $(n=32)$.

\begin{tabular}{|c|c|c|c|c|c|}
\hline & Mean & Max. & Min. & SD & CV \\
\hline Depth (m) & 8.8 & 15.6 & 2.1 & 3.6 & 0.4 \\
\hline LOI $(\%)$ & 12.1 & 18.7 & 2.9 & 4.4 & 0.4 \\
\hline Org. Carbon $(\%)$ & 2.8 & 6.5 & 0.4 & 1.3 & 0.5 \\
\hline Wet Bulk Density $\left(\mathrm{g} \mathrm{cm}^{-3}\right)$ & 1.2 & 1.61 & 1.08 & 0.2 & 0.2 \\
\hline Phosphorus (mg kg-1) & 822 & 1,344 & 224 & 329 & 0.4 \\
\hline $\operatorname{Mn}\left(\mathrm{mg} \mathrm{kg}^{-1}\right)$ & 341 & 488 & 190 & 71.3 & 0.2 \\
\hline $\mathrm{Fe}\left(\mathrm{g} \mathrm{kg}^{-1}\right)$ & 42 & 68.3 & 11.4 & 12.6 & 0.3 \\
\hline Proportion of particles $<63 \mu \mathrm{m}(\%)$ & 74 & 99.7 & 15.5 & 32.6 & 0.5 \\
\hline Proportion of particles $<250 \mu \mathrm{m}>63 \mu \mathrm{m}(\%)$ & 10.2 & 95.2 & 0.1 & 17.6 & 1.7 \\
\hline Proportion of particles $<500 \mu \mathrm{m}>250 \mu \mathrm{m}(\%)$ & 8.6 & 36.8 & 0 & 11.2 & 1.3 \\
\hline Proportion of particles $<2 \mathrm{~mm}>500 \mu \mathrm{m}(\%)$ & 8.1 & 42.5 & 0 & 12.9 & 1.6 \\
\hline Proportion of particles $>2 \mathrm{~mm}(\%)$ & 1.7 & 15 & 0 & 3.2 & 1.9 \\
\hline
\end{tabular}

$\mathrm{CV}$, coefficient of variation. 


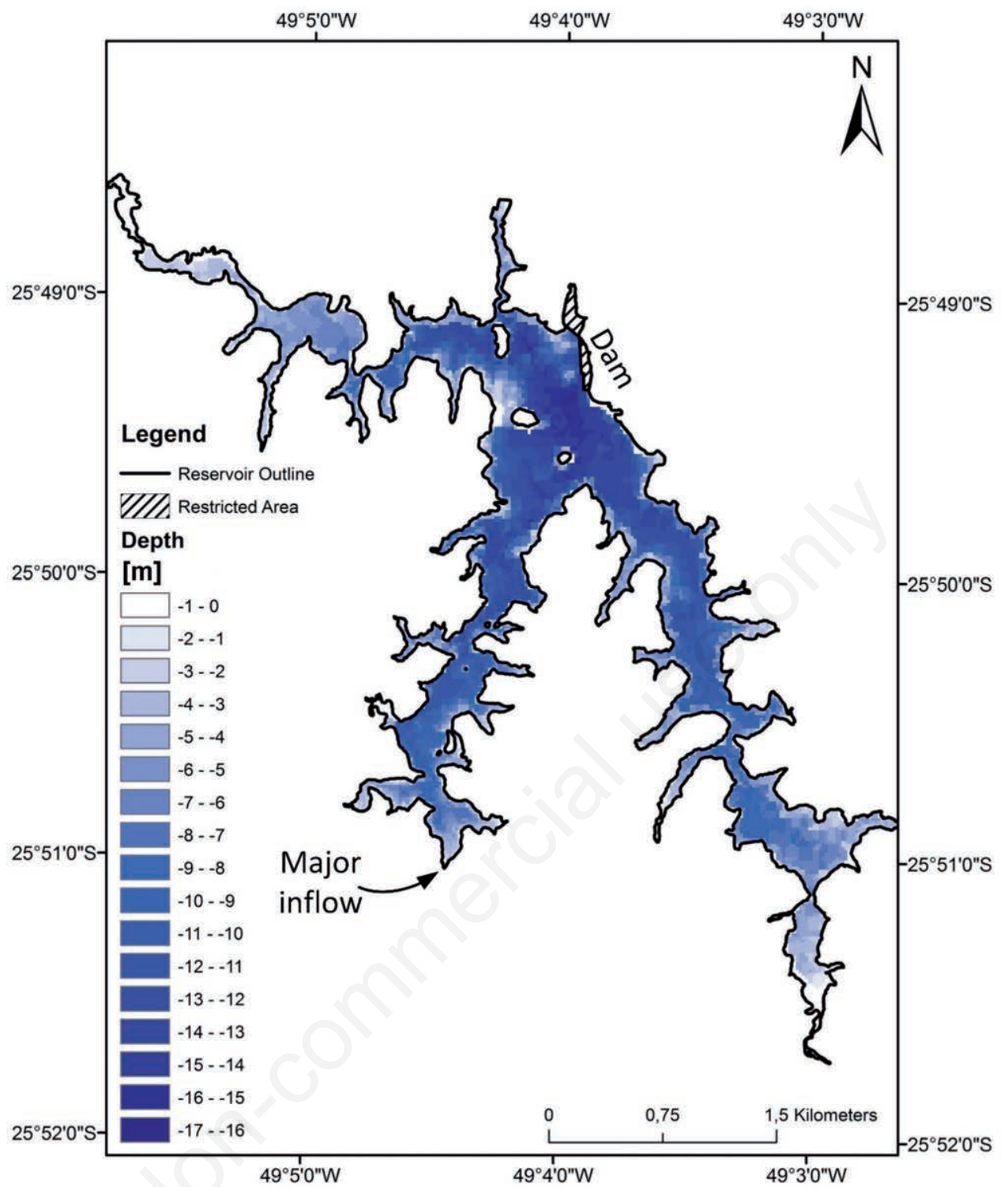

Fig. 4. Bathymetric map of the Vossoroca reservoir.

Tab. 4. Pearson r-values for the sediment and acoustic parameters based on the results obtained from the core samples of the Vossoroca reservoir; in each case, the correlation for the best performing pulse length is shown only; statistical significance is given for $r>0.63$ $\mathrm{P}<0.05, \mathrm{n}=10)$.

\begin{tabular}{|c|c|c|c|c|c|c|c|c|c|c|c|c|c|c|}
\hline \multirow[b]{2}{*}{$\mathrm{kHz}$} & \multicolumn{2}{|c|}{ Density } & \multicolumn{2}{|c|}{ Total P } & \multicolumn{2}{|c|}{ LOI } & \multicolumn{2}{|c|}{$\%<63 \mu \mathrm{m}$} & \multicolumn{2}{|c|}{ Total C } & \multicolumn{2}{|c|}{ Fe } & \multicolumn{2}{|c|}{ Mn } \\
\hline & 200 & 38 & 200 & 38 & 200 & 38 & 200 & 38 & 200 & 38 & 200 & 38 & 200 & 38 \\
\hline E1' & -0.31 & -0.92 & -0.24 & 0.79 & 0.33 & 0.84 & 0.42 & 0.90 & 0.33 & 0.70 & -0.42 & 0.69 & 0.19 & 0.72 \\
\hline E1 & -0.64 & -0.73 & 0.66 & 0.80 & 0.64 & 0.67 & 0.91 & 0.95 & 0.32 & 0.30 & 0.74 & 0.86 & 0.29 & 0.38 \\
\hline attdecSv1 & -0.50 & -0.93 & 0.26 & 0.81 & 0.50 & 0.84 & 0.55 & 0.94 & 0.38 & 0.69 & -0.32 & 0.73 & 0.15 & 0.73 \\
\hline attSv2 & 0.65 & -0.49 & -0.76 & 0.27 & -0.56 & 0.49 & -0.82 & -0.41 & -0.25 & 0.74 & -0.25 & -0.56 & -0.39 & 0.73 \\
\hline decSv2 & -0.34 & -0.94 & -0.42 & 0.80 & 0.36 & 0.85 & 0.50 & 0.89 & 0.34 & 0.77 & -0.45 & 0.66 & -0.20 & 0.85 \\
\hline E2 & 0.39 & -0.94 & -0.54 & 0.77 & 0.31 & 0.86 & -0.57 & 0.84 & 0.29 & 0.77 & -0.60 & 0.61 & -0.29 & 0.84 \\
\hline E1'/E1 & -0.49 & 0.68 & 0.48 & -0.48 & 0.39 & -0.65 & 0.80 & -0.50 & -0.24 & -0.72 & 0.78 & 0.53 & -0.18 & -0.77 \\
\hline E1/E2 & 0.67 & -0.46 & -0.72 & 0.38 & -0.66 & 0.58 & -0.91 & -0.38 & 0.33 & 0.81 & -0.81 & -0.37 & -0.33 & 0.80 \\
\hline
\end{tabular}


Even though some of the best correlations for grab samples reach the same range (best value: $r=0.89$ ), average values for certain parameters are clearly lower than the core sample results (Tab. 5).

$E 1 / E 2$ is the best performing hydro-acoustic parameter at $200 \mathrm{kHz}$ frequency for the core samples with an average correlation of $63 \%$ over all pulse lengths and sediment parameters. For the $38 \mathrm{kHz}$ frequency, the best overall parameters are E1', attdecSv1, and decSv2 with an average performance of $79 \%$. For the correlation with the sediment characteristics obtained from grab samples, the $E 1$ parameter produced the best results at both frequencies, with $68 \%$ at $200 \mathrm{kHz}$ and $67 \%$ at $38 \mathrm{kHz}$. The best performing parameter couples for core samples averaged over all pulse lengths are $E 1 / E 2$ with $\%<63 \mu \mathrm{m}$, with $74 \%$ at $200 \mathrm{kHz}$ frequency, and $E 1$ combined with $\%<63$ $\mu \mathrm{m}$ resulting in a correlation of $95 \%$. For the grab samples, the best single sediment parameter is $\%<63 \mu \mathrm{m}$ with $73 \%$ over all pulse lengths at $38 \mathrm{kHz}$ combined with the E1 parameter. The best detectable sediment parameter at $200 \mathrm{kHz}$ is the organic carbon content with $85 \%$ based on the attdecSv 1 values.

\section{Effect of pulse duration}

At all sampling positions, the listed pulse lengths (Tab. 2) were used one after the other to investigate differences of the correlations with sediment parameters. Since the pulse length has an influence on the hydroacoustic resolution, a variation in correlation performance can be expected (Guillard et al., 2009). Fig. 5 compares the effect of different pulse lengths on the $R^{2}-$ values for selected hydro-acoustic features obtained using the 200 and $38 \mathrm{kHz}$ frequencies with core samples for ground truthing. For the $200 \mathrm{kHz}$ frequency, the shortest pulse length produces the best correlations independent of the sediment parameter. This accounts for the E1 as well as for the E1/E2 parameter, which includes energy patterns of the second bottom echo. The same result is shown by the $E 1$ parameter for the $38 \mathrm{kHz}$ frequency, with the correlation being significantly better with shorter pulse length. Different results are obtained for the E1/E2 parameter at $38 \mathrm{kHz}$. All hydro-acoustic features measured at $38 \mathrm{kHz}$, inclusive of the second bottom signal (attSv2, decSv2, E2, E1/E2), show better correlations for the longer pulse duration.

\section{Cores versus grabs}

Fig. 6 illustrates the overall result of correlations of hydro-acoustic values with sediment data obtained from core samples being significantly higher. This holds for both frequencies used in this survey. While the difference between core-related results and grab-related results is high for the attSv2-parameter, the difference is only marginal for the $E 1$ ' parameter. As the part of the signal processed for the $E 1$ ' parameter represents the first layer of the sediment only, the small difference between core and grab results is in accordance with the sampling depth of the grab sampling device $(0-20 \mathrm{~cm})$. Both sampling techniques will produce comparable sediment samples for the upper sediment layer. In contrast to this, the results for all acoustic parameters, including deeper layers of the sediment, differ considerably between core and grab samples. In these cases, the correlation with the sediment parameters obtained from the core samples and, hence, from deeper layers fit well to the values of the hydro-acoustic survey.

\section{DISCUSSION}

Combining two frequencies, various pulse lengths and multiple physical and chemical sediment parameters surveyed in the Vossoroca reservoir in Brazil resulted in a set of good and moderately correlated parameters. Significant differences between the 200 and $38 \mathrm{kHz}$ frequencies and the tested sediment parameters were found. Among these parameters were wet bulk density, granulometry, phos-

Tab. 5. Pearson r-values for the sediment and acoustic parameters based on the results obtained from the grab samples of the Vossoroca reservoir; in each case, the correlation for the best performing pulse length is shown only; statistical significance is given for $\mathrm{r}>0.55$ ( $\mathrm{P}$ $0.01, \mathrm{n}=21)$.

\begin{tabular}{|c|c|c|c|c|c|c|c|c|c|c|c|c|}
\hline \multirow[b]{2}{*}{$\mathrm{kHz}$} & \multicolumn{2}{|c|}{ Total P } & \multicolumn{2}{|c|}{ LOI } & \multicolumn{2}{|c|}{$\%<63 \mu \mathrm{m}$} & \multicolumn{2}{|c|}{ Total C } & \multicolumn{2}{|c|}{$\mathrm{Fe}$} & \multicolumn{2}{|c|}{ Mn } \\
\hline & 200 & 38 & 200 & 38 & 200 & 38 & 200 & 38 & 200 & 38 & 200 & 38 \\
\hline E1' & 0.61 & 0.52 & 0.45 & 0.52 & -0.47 & 0.72 & 0.89 & 0.29 & 0.51 & 0.43 & -0.25 & 0.26 \\
\hline E1 & 0.75 & 0.75 & 0.72 & 0.73 & 0.72 & 0.79 & 0.80 & 0.66 & 0.73 & 0.73 & 0.36 & 0.39 \\
\hline attdecSv1 & 0.61 & 0.65 & 0.46 & 0.58 & 0.40 & 0.78 & 0.89 & 0.40 & 0.51 & 0.57 & 0.23 & 0.45 \\
\hline attSv2 & 0.38 & -0.21 & 0.22 & -0.21 & -0.21 & 0.14 & 0.79 & -0.52 & 0.32 & -0.12 & -0.32 & 0.17 \\
\hline decSv2 & 0.55 & 0.60 & 0.40 & 0.56 & -0.37 & 0.73 & 0.89 & 0.39 & 0.47 & 0.53 & 0.21 & 0.36 \\
\hline E2 & 0.52 & 0.58 & 0.36 & 0.53 & -0.35 & 0.72 & 0.88 & 0.37 & 0.44 & 0.51 & 0.18 & 0.36 \\
\hline E1'/E1 & 0.73 & 0.47 & 0.64 & 0.40 & 0.63 & 0.34 & 0.84 & 0.61 & 0.72 & 0.52 & 0.29 & 0.26 \\
\hline E1/E2 & -0.78 & -0.37 & -0.74 & -0.43 & -0.79 & -0.28 & -0.73 & -0.57 & -0.74 & -0.40 & -0.40 & 0.09 \\
\hline
\end{tabular}


phorus content, organic $\mathrm{C}$ as well as iron and manganese contents. Comparison of the correlations of sediment parameters obtained from core or grab sampling revealed that core samples are clearly better suited for ground truthing. Additionally, analysis of the correlation performance of a range of tested pulse lengths showed that most echo features produce better results at shorter pulse lengths. In additional experiments, depth dependence on seabed classification was investigated, but since the results did not show any clear tendencies, they are not presented in this article.

As most of the available literature does not focus on the acoustic determination of sediment properties like carbon content or total P content, data available for comparison are scarce. Still, the results can be compared partly with the results from Anderson and Pacheco (2011). Comparable are the $r$-values at 200 and $38 \mathrm{kHz}$ for the acoustic parameters $E 1$ ' $/ E 1$ and $E 1 / E 2$ and the sediment parameters Clay content, LOI, and total $P$. The results show similar tendencies. While the $200 \mathrm{kHz}$ frequency can detect the granulometric properties, the $38 \mathrm{kHz}$ fails to reach a significant level of correlation (Tab. 4). The LOI and total $\mathrm{P}$ content are largely described by the E1/E2 parameter, but not by the $\mathrm{E} 1$ '/E1. This is in conflict with the results

\section{E1 - Cores 200 kHz}

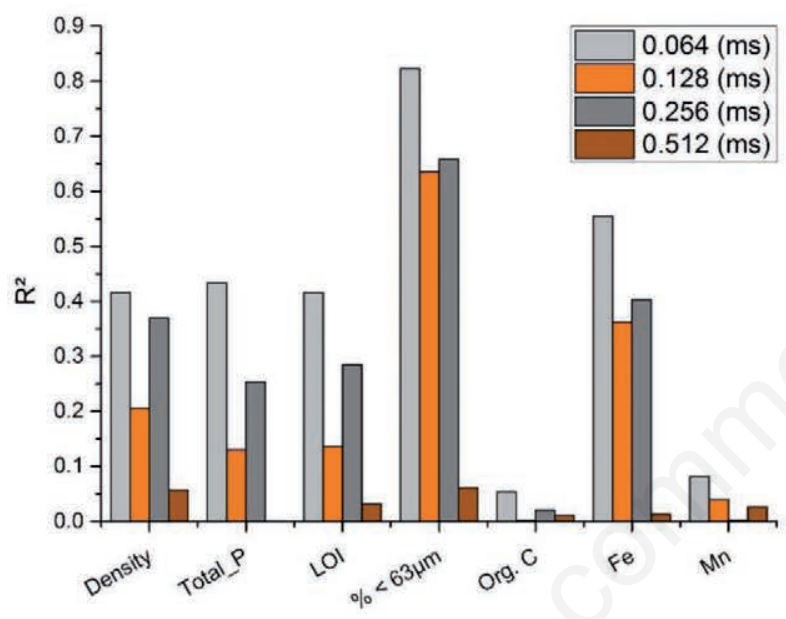

E1/E2 - Cores $200 \mathrm{kHz}$

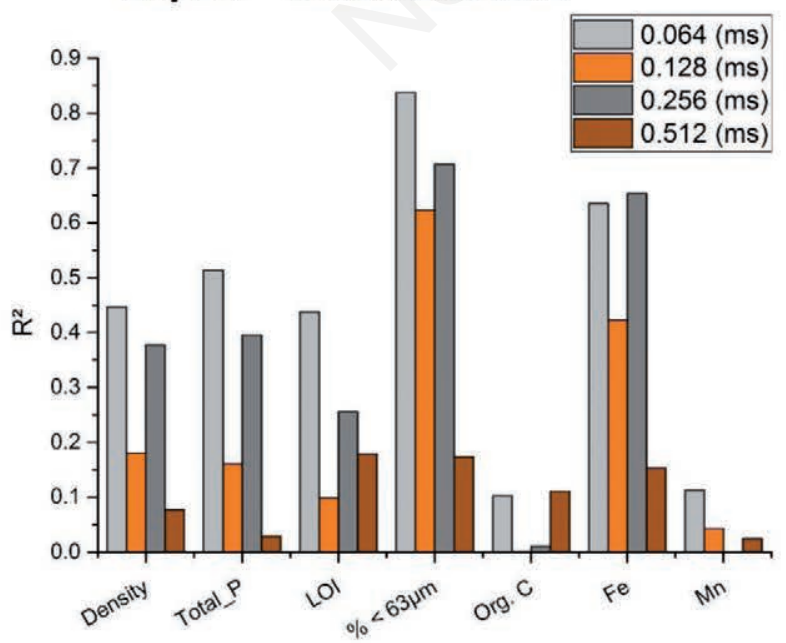

E1 - Cores $38 \mathrm{kHz}$

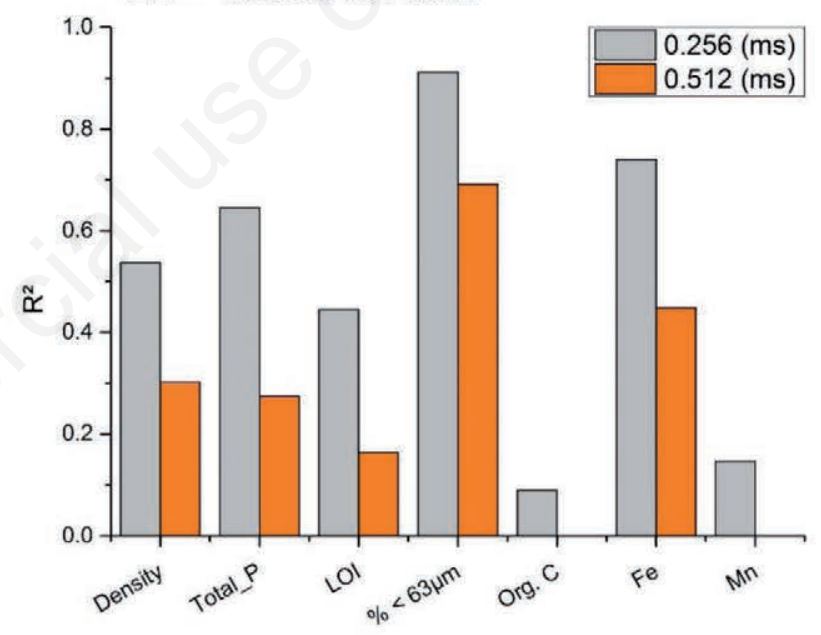

E1/E2 - Cores $38 \mathrm{kHz}$

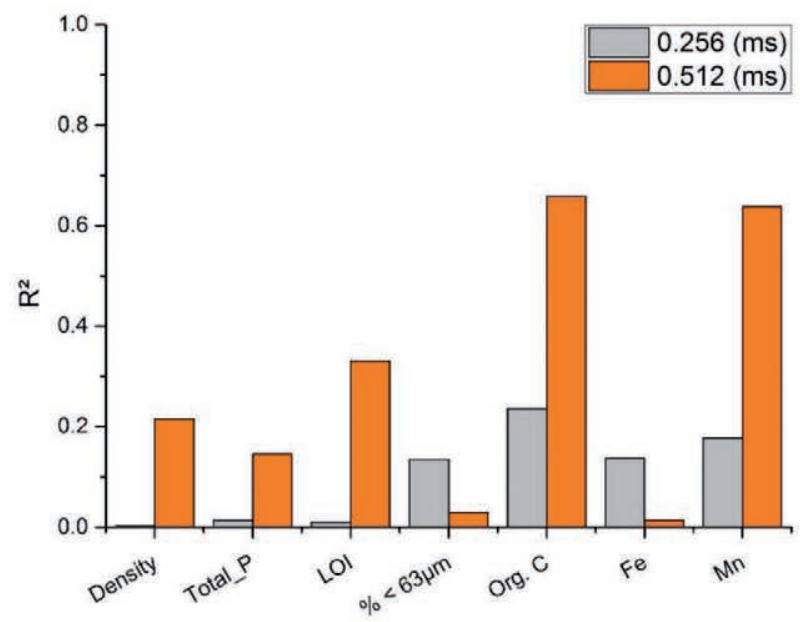

Fig. 5. Comparison of $\mathrm{R}^{2}$-values obtained with different pulse lengths for selected hydro-acoustic features using 200 and $38 \mathrm{kHz}$ frequencies and core samples for ground truthing. 
of Anderson and Pacheco (2011). Thirty eight kHz $r$-values for $L O I$ and $P$ content show different patterns, as the E1'/E1 parameter produces better results compared to the E1/E2. In general, the P content could be correlated with high $r$-values, which contradicts the results presented by Anderson and Pacheco, 2011. Even if the exact values differ from the results of Anderson and Pacheco (2011), it can be stated that the granulometric properties of the sediment can be related directly to the acoustic parameters. Taking into account other acoustic parameters (E1', E1, E2) and their correlations with granulometric features, even higher correlations of up to $93 \%$ were found (Tab. 4). The best correlations were obtained for the wet bulk density and the share of particles $<63 \mu \mathrm{m}$. The negative correlation with the wet bulk density can be attributed to the presence of gas bubbles in the sediment matrix. Bubbles cause a lower wet bulk density and a higher reflection intensity, since accumulations of gas bubbles represent strong reflectors of sound impulses (Anderson et al., 1998; Anderson and Martinez, 2015). This assumption fits to the strongly positive correlation with the share of the silt and clay fraction. Finer sediment layers are prone to have an increased content of organic carbon and, hence, a higher potential productivity of gas in the sediment.

Averaging of the correlation results for silt and clay at $38 \mathrm{kHz}$ in Anderson and Pacheco, 2011 yielded -0.31, which is very close to the $r$-value of -0.28 obtained here. Additionally, the correlations for total $\mathrm{P}(r=-0.37,38 \mathrm{kHz})$ and LOI $(r=-0.43,38 \mathrm{kHz})$ reproduce the published results well. It can be concluded that i) correlation and ii) the coefficient values yielded similar results for comparable parameter combinations. In contrast to literature, this study shows highly significant correlations for total $\mathrm{P}(r>0.93)$ (attdecSv1, decSv2, E2) and various sediment attributes (Tab. 4). In general, the results at $38 \mathrm{kHz}$ frequency produce slightly higher correlation coefficients than at 200 $\mathrm{kHz}$ frequency. For the grain size parameters, the coefficients have similar values (van Walree et al., 2005). This agreement between the hydro-acoustic response of the phosphorus content and the particle size distribution seems to be reasonable, since most phosphorus species are primarily bound to the silt and clay fraction. Further-

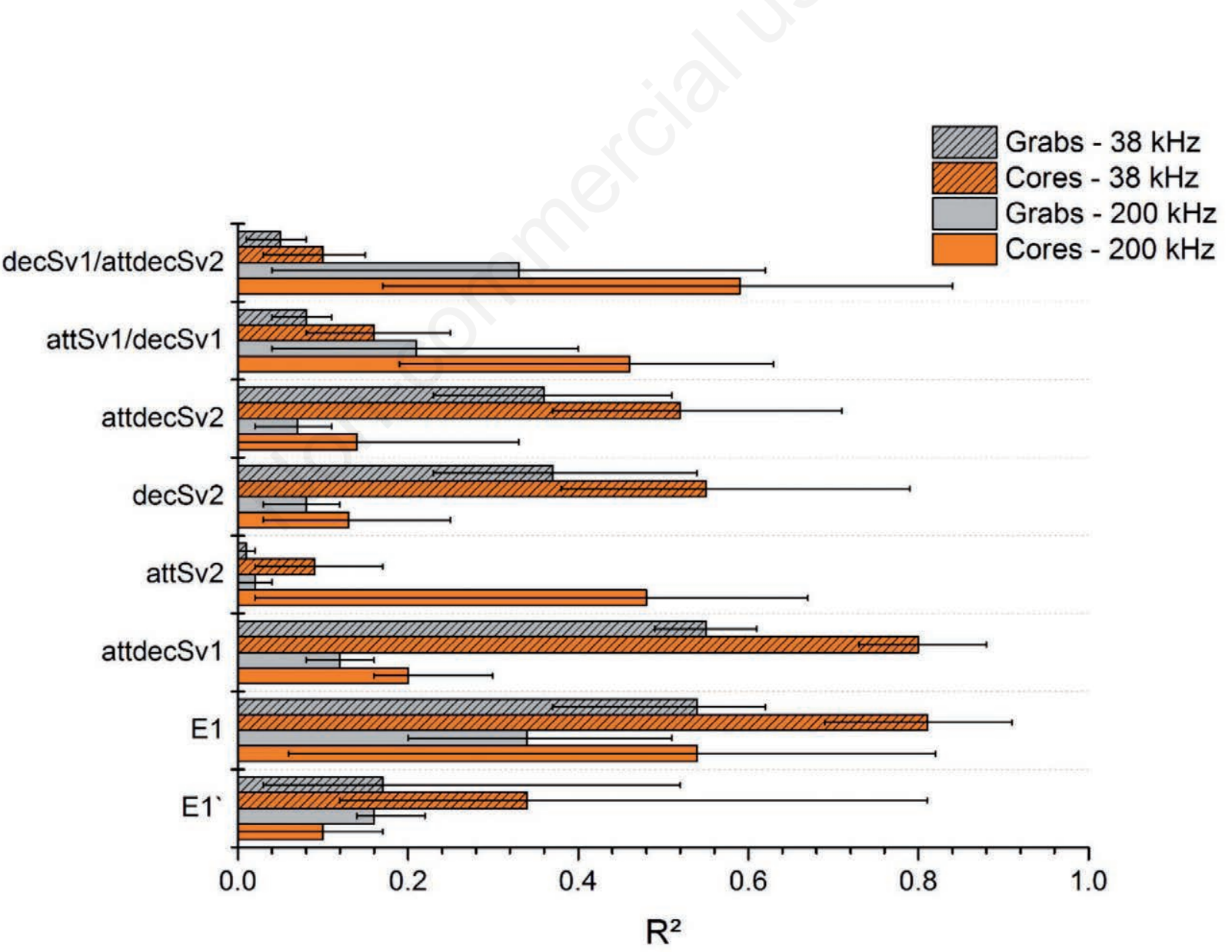

Fig. 6. Comparison of the correlation results of the eight hydro-acoustic parameters with $\%<63 \mu \mathrm{m}$ for both frequencies and cores and grabs. The bars show the average $\mathrm{R}^{2}$-value while the error bars represent the maximum and minimum values from the different configurations. 
more, the density of the sediment was clearly better detected by the $38 \mathrm{kHz}$ frequency, reaching correlations of 95\% (Bentrem et al., 2002). The better correlation is due to the position of the density measurements in the cores. Sampling material was extracted from around $10 \mathrm{~cm}$ below the sediment / water interface, which reduces the potential share of the sediment volume represented in the returned $200 \mathrm{kHz}$ acoustic signal, because the $200 \mathrm{kHz}$ frequency is not able to penetrate the sediment very deeply. Especially a shorter pulse length reduces the signal-relevant sediment depth.

Grab sampling for ground truthing is a widely spread standard method. However, the presented results show a significant difference between ground truthing results from cores and grabs (Fig. 6). This especially applies to physical sediment parameters, but also to the LOI and organic C. Differences between cores and grabs are highest for all correlations, including second bottom-echo features, and lowest for the E1' parameter. The results can be explained by the fact that the sediment relevant to the E1' parameter is the same for both sampling approaches, while the sediment volume ensonified during the E1 phase $(4 * \tau=$ up to $3 \mathrm{~m})$ cannot be sampled with a grab sampler. Since the influence of the sediment volume properties increases from the first to the second bottom echo, the difference between cores and grabs is enhanced. Here, the internal sediment layering plays an important role (Ostrovsky and Tęgowski, 2010). Due to the higher penetration depth of the $38 \mathrm{kHz}$ frequency, the influence of the sediment volume is even stronger. For this reason, divergence between core and grab results is larger than at the $200 \mathrm{kHz}$ frequency. Additionally, it must be stated that the sediment type may play a major role regarding the influence of the sampling method. In the presented case, sediment could be properly sampled with both techniques. However, higher shares of coarse material (e.g., gravel) or lower cohesion of the sample volume may lead to biased results between core and grab samples.

Regarding the discrepancy between the ensonified footprint area and the surface sampled by the grabber or sediment corer, a potential bias might occur. During this study, the mean sampling depth was $8.8 \mathrm{~m}$. For the $200 \mathrm{kHz}$ frequency, it caused a footprint of $\sim 3.8 \mathrm{~m}^{2}$ and for the $38 \mathrm{kHz}$ frequency of $\sim 12.2 \mathrm{~m}^{2}$. It can be assumed that, except for very narrow side arms, the sediment composition does not change significantly within 2-3.5 m. Consequently, the relatively small sampling area of the corer and grabber can be neglected until a certain depth. For sediment investigations at greater depth, a higher number of sediment samples per sampling location seems to be advisable.

Based on the results presented, the echo sounder settings can be optimised for sediment characterisation. Specific settings can be chosen for the sediment parameter to be determined. In dependence to the used frequency, a shorter pulse length will produce better classification re- sults. Optimal configurations allow for a good estimation $(\mathrm{r}=0.9-0.95)$ of the granulometry, bulk density or even LOI. Lower but still significant results were achieved for total $\mathrm{P}(\mathrm{r}=0.81)$.

Additionally, the results show that core sampling produces significantly better results. The presented results prove that under the given conditions, sediment characteristics can be detected. Especially in morphometrically complex systems, this will ensure improved sediment monitoring and, later on, better management strategies, as they are based on sediment information. Here, information on the sediment type (granulometry) and potential organic content or even phosphorus content can help in planning sediment disposal. Sediment information can also be used in the context of methane production, as the productivity of the sediment is linked to the amount of organic carbon in the sediment (Sobek et al., 2012).

\section{CONCLUSIONS}

- The exact configuration of the echo sounder has a strong influence on potential sediment characterisation and sediment feature correlation.

- Shorter pulse lengths produce better ground truthing results.

- Core samples produce significantly better results for ground truthing than grab samples, especially at the lower frequency and for decay-related hydro-acoustic features.

- In addition to physical parameters, chemical parameters can be included in hydro-acoustic sediment characterisation.

- The produced information may significantly improve sediment management even in large-scale reservoirs.

\section{ACKNOWLEDGMENTS}

Many thanks go to the UFPR, DHS research team with Prof. Fernandes, Prof. Bleninger, and Julio Werner as well as to the technical staff of the DHS, who supported the research activities. We also thank Prof. Helge Balk from the University of Oslo for support with the Sonar5-Pro software. For the GPS support, we thank Prof. Claudia Krueger from the Departamento de Geomática, UFPR. Additional thanks go to Prof. Fernandes, Prof. Bleninger, and Prof. Helge Balk for reviewing this article.

\section{REFERENCES}

Amiri-Simkooei AR, Snellen M, Simons DG, 2011. Principal component analysis of single-beam echo-sounder signal features for seafloor classification. IEEE J. Ocean. Eng. 36:259-272. 
Anderson AL, Abegg F, Hawkins JA, Duncan ME, Lyons AP, 1998. Bubble populations and acoustic interaction with the gassy floor of Eckernförde Bay. Cont. Shelf Res. 18:18071838.

Anderson JT, van Holliday D, Kloser R, Reid DG, Simard Y, 2008. Acoustic seabed classification: current practice and future directions. ICES J. Mar. Sci. 65:1004-1011.

Anderson MA, Martinez D, 2015. Methane gas in lake bottom sediments quantified using acoustic backscatter strength. J. Soil. Sediment. 15:1246-1255.

Anderson MA, Pacheco P, 2011. Characterization of bottom sediments in lakes using hydroacoustic methods and comparison with laboratory measurements. Water Res. 45:4399-4408.

Balk H, Lindem T, Sánchez-Carnero N, 2011. Sonar4 and Sonar5 post processing systems. Operator manual version 6.0.1. Extension for Seabed Classification Tool.

Bentrem FW, Sample J, Kalcic MT, Duncan ME, 2002. Highfrequency acoustic sediment classification in shallow water. Oceans-IEEE 1:7-11.

Burczynski J, 1999. Bottom classification. Available from: www.biosonicsinc.com

Deutsches Institut fuer Normung e.V., 2005. Aggregates test methods. Determination of particle size distribution by wet sieving. Beuth Verlag GmbH.

Deutsches Institut fuer Normung e.V., 2007. Characterization of waste. Determination of loss on ignition in waste, sludge and sediments. Beuth Verlag GmbH.

Dunbar JA, Allen PM, Higley PD, 1999. Multifrequency acoustic profiling for water reservoir sedimentation studies. J. Sediment. Res. 69:521-527.

Freitas R, Sampaio L, Oliveira J, Rodrigues AM, Quintino V, 2006. Validation of soft bottom benthic habitats identified by single-beam acoustics. Mar. Pollut. Bull. 53:72-79.

Friedl G, Wüest A, 2002. Disrupting biogeochemical cycles Consequences of damming. Aquat. Sci. 64:55-65.

Guillard J, Godlewska M, Colon M, Doroszczyk L, Dlugoszewski B, 2009. Standartization of hydroacoustic methods - Effect of pulse duration. In: Proc. 3rd Int. Conf. and Exhibition of Underwater Acoustic Measurements: Technologies \& Results, Nafplion, Greece.

Hamilton LJ, Parnum I, 2011. Acoustic seabed segmentation from direct statistical clustering of entire multibeam sonar backscatter curves. Cont. Shelf Res. 31:138-148.

Harris MM, Avera WE, Abelev A, Bentrem FW, Bibee LD,
2008. Sensing shallow seafloor and sediment properties. Recent history. Oceans-IEEE 2008(Suppl.):1-11.

Niederreiter R, 2012. Uwitech sampling equipments. Available from: www.uwitec.at/html/frame.html

Odhiambo BK, Boss SK, 2004. Integrated echo sounder, GPS, and GIS for Reservoir sedimentation studies: examples from two Arkansas lakes. J. Am. Water Resour. As. 40:981-997.

Orlowski A, 1984. Application of multiple echoes energy measurements for evaluation of sea bottom type. Oceanologia 1984:61-78.

Ostrovsky I, Tęgowski J, 2010. Hydroacoustic analysis of spatial and temporal variability of bottom sediment characteristics in Lake Kinneret in relation to water level fluctuation. GeoMar. Lett. 30:261-269.

Parnum I, Siwabessy J, Gavrilov A, Parsons M, 2009. A comparison of single beam and multibeam sonar systems in seafloor habitat mapping, p. 155-162. In: Proc. 3rd Int. Conf. and Exhibition of Underwater Acoustic Measurements: Technologies \& Results, Nafplion, Greece.

Poulain T, Argillier C, Gevrey M, Guillard J, 2011. Identifying lakebed nature: is it feasible with a combination of echosounder and Sonar5-pro? Adv. Oceanogr. Limnol. 2:49-53.

Preston JM, 2009. Automated acoustic seabed classification of multibeam images of Stanton Banks. App. Acoust. 70:12771287.

Republic of Brazil Canambra Engineering Consultant, United Nations Development Programme,1969. Power study of South Brazil.

Sobek S, DelSontro T, Wongfun N, Wehrli B, 2012. Extreme organic carbon burial fuels intense methane bubbling in a temperate reservoir. Geophys. Res. Lett. 39:L01401.

Tęgowski J, 2005. Acoustical classification of the bottom sediments in the southern Baltic Sea. Quatern. Int.130:153-161.

US Environmental Protection Agency, 2001. Measurement and monitoring technologies for the 21 st century. Available from: https://clu-in.org/programs/21m2/

van Walree PA, Tęgowski J, Laban C, Simons DG, 2005. Acoustic seafloor discrimination with echo shape parameters: A comparison with the ground truth. Cont. Shelf Res. 25:2273-2293.

WCD (World Commission on Dams), 2000. Dams and development: a new framework for decision-making. Earthscan Publications, London. 